Revista Brasileira de Agricultura Irrigada v.11, nº.8, p. 2162 - 2171, 2017

ISSN 1982-7679 (On-line)

Fortaleza, CE, INOVAGRI - http://www.inovagri.org.br

DOI: $10.7127 /$ rbai.v11n800705

Protocolo 705.17 - 26/06/2017 Aprovado em 31/08/2017

\title{
EFICIÊNCIA DE UTILIZAÇÃO DE ÁGUA NO CULTIVO DE PEPINO JAPONÊS EM AMBIENTE PROTEGIDO
}

\author{
Cássio de Castro Seron ${ }^{1}$, Roberto Rezende ${ }^{2}$, André Maller ${ }^{3}$, Marcelo Zolin Lorenzoni ${ }^{1}$, \\ Álvaro Henrique Cândido de Souza ${ }^{1}$, Fernando André Silva Santos ${ }^{1}$
}

\begin{abstract}
RESUMO
A baixa eficiência na utilização da água na irrigação é um fator é importante para minimizar o desperdício e garantir quantidade suficiente para os sistemas agrícolas, devido ao custo da irrigação e de energia estarem cada vez mais elevados. Uma maneira de garantir melhor eficiência na utilização de água pela planta e que vem sendo muito difundida a realização de irrigações com déficit. Com isto, o presente trabalho foi conduzido com o objetivo de avaliar o efeito de lâminas de irrigação com relação sobre a produtividade, massa seca de raízes e a eficiência de utilização da água pela cultura de pepino japonês cultivado em ambiente protegido. Foram testados quatro níveis de reposição das lâminas da evapotranspiração da cultura $\left(75 \%, 100 \%, 125 \%\right.$ e $150 \%$ da ETc) com a evapotranspiração de referência $\left(\mathrm{ET}_{0}\right)$ estimada pelo modelo de Penman-Monteith. Adotou-se o delineamento inteiramente casualizado com quatro repetições. Foi avaliado a produtividade, a massa seca de raiz e a eficiência de utilização da água, obtendo os seguintes resultados. A maior produtividade $(2,19$ $\left.\mathrm{kg} \mathrm{planta}^{-1}\right)$, e massa seca de raízes $\left(12,8 \mathrm{~g} \mathrm{planta}^{-1}\right)$ foi obtida com o fornecimento de $128 \% \mathrm{e}$ $114 \%$ da ETc respectivamente. A maior eficiência de utilização da água foi obtida com a lâmina de $121 \%$ da ETc, notando que um aumento sobre a lâmina de referência (100\% ETc) é uma alternativa na gestão de recursos hídricos para aumentar a produtividade da cultura.
\end{abstract}

Palavras-chave: Cucumis sativus L.; produção; massa de raiz.

\section{EFFICIENCY OF USE OF WATER IN THE CULTIVATION OF JAPANESE CUCUMBER IN GREENHOUSE}

\begin{abstract}
The low efficiency in the use of the water in the irrigation is a factor is important to minimize the waste and to guarantee enough amount for the agricultural systems, due to the cost of the

${ }^{1}$ Doutorandos em Agronomia, UEM, e-mail: cassioseron@msn.com; alvarohcs@hotmail.com; marcelorenzoni@hotmail.com; fernandoandre_agro2007@hotmail.com

${ }^{2}$ Doutor em Agronomia, Prof. Associado da UEM, e-mail: rrezende@uem.br

${ }^{3}$ Doutor em Agronomia, UEM, e-mail: anmaller@ hotmail.com
\end{abstract}


irrigation and of energy they be more and more elevated. A way to guarantee better efficiency in the use of water for the plant and that is being very spread the accomplishment of irrigations with deficit. With this, the present work was driven with the objective of evaluating the effect of irrigation sheets with relationship about the productivity, mass dries of roots and the efficiency of use of the water for the culture of japanese cucumber cultivated in greenhouse. Four levels of replacement of the sheets of the evapotranspiration of the culture $(75 \%, 100 \%$, $125 \%$ and $150 \%$ of the ETc) were tested with the evapotranspiration of dear reference $\left(\mathrm{ET}_{0}\right)$ by the model of Penman-Monteith. The design was adopted randomized entirely with four repetitions. The productivity, the mass was evaluated dries of root and the efficiency of use of the water, obtaining the following results. The largest productivity $\left(2,19 \mathrm{~kg} \mathrm{plants}^{-1}\right)$, and mass dries of roots $\left(12,8 \mathrm{~g} \mathrm{plants}^{-1}\right)$ it was obtained with the supply of $128 \%$ and $114 \%$ of the ETc respectively. The largest efficiency of use of the water was obtained with the sheet of $121 \%$ of the ETc, noticing that an increase on the reference (100\% Etc) sheet is an alternative in the administration of resources hydrics to increase the productivity of the culture.

Keywords: Cucumis sativus L.; water productivity; production; root mass.

\section{INTRODUÇÃO}

A cultura do pepino japonês possui maior demanda no mercado consumidor em comparação com as outras variedades devido a menor presença de sementes nos frutos, tornando-os mais saborosos (SILVA et al., 2011). O cultivo protegido possui como principal vantagem o aumento de produtividade facilitado pela proteção de condições ambientais adversas e controle de fatores abióticos como o fornecimento adequado de água (FILGUEIRA, 2008).

O estudo do desenvolvimento da cultura em ambiente protegido é fundamental para quantificar a necessidade hídrica adequada em cada fase fenológica (MENDES, 2009). Salokhe et al. (2005) estudando as necessidades hídricas das culturas em ambiente protegido concluiu que uma lâmina deficitária podem suprir a cultura quando comparadas com o cultivo a campo.

A irrigação com déficit é uma técnica que vem se difundindo e se consolidando por apresentar resultados positivos. Alguns estudos permitem concluir que o não fornecimento total da demanda hídrica, interfere na produtividade e na eficiência de utilização de água (ÇAKIR et al., 2017).

Pode-se constatar que aumentando a lâmina aplicada para à cultura pode haver um aumento da eficiência de utilização da água, no entanto, um incremento acima de $100 \%$ da ETc na lâmina pode acarretar uma diminuição nessa eficiência (ALI; TALUKDER, 2008).

Em olerícolas com o aumento da disponibilidade hídrica faz com que a planta se desenvolva, porém, quando se irriga acima da umidade na capacidade de campo ocorre a saturação do solo (com baixa aeração) e as plantas tendem a diminuir seu crescimento. Por isso, ressalta-se que o ajuste das necessidades hídricas de uma cultura evita a saturação do solo e consequentemente o desperdício de água (BERNARDO, 1995).

Objetivou-se, avaliar o efeito de lâminas de irrigação sobre a produção, o crescimento radicular e a eficiência de utilização da água da cultura do pepino japonês cultivado em ambiente protegido.

\section{MATERIAL E MÉTODOS}

O experimento foi conduzido de outubro de 2015 a fevereiro de 2016 em ambiente protegido, no Centro Técnico de Irrigação da Universidade Estadual de Maringá, na cidade de Maringá - PR. Esta localidade é classificada por Köppen como Cfa Mesotérmico Úmido, com chuvas abundantes no verão e invernos secos.

O ambiente protegido consistia em uma cobertura em arco com tubos galvanizados, laterais envoltas com tela antiafídeo contendo rodapé de alvenaria de $0,25 \mathrm{~m}$ de altura. A 
cobertura superior é de plástico de polietileno de baixa densidade UV (150 micra).

$\mathrm{O}$ solo da área experimental foi classificado como Nitossolo Vermelho distroférrico (EMBRAPA, 2013).

As características químicas e composição granulométrica do solo são apresentadas nas Tabelas 1 e 2 .

Tabela 1. Resultado da análise química do solo realizada antes da implantação da cultura do pepino.

\begin{tabular}{|c|c|c|c|c|c|c|c|c|c|}
\hline $\mathrm{pH}$ & MO & $\mathrm{P}$ & $\mathrm{K}^{+}$ & $\mathrm{Ca}^{+2}$ & $\mathrm{Mg}^{+2}$ & $\mathrm{H}^{+}+\mathrm{Al}^{3+}$ & CTC & SB & $\mathrm{V}$ \\
\hline $\mathrm{H}_{2} \mathrm{O}$ & \multicolumn{2}{|c|}{$\mathrm{g} \mathrm{dm}^{-3}$} & \multicolumn{6}{|c|}{$\mathrm{cmol}_{\mathrm{c}} \mathrm{dm}^{-3}$} & $\%$ \\
\hline 6,50 & 8,46 & 36,99 & 0,26 & 6,50 & 1,96 & 2,74 & 11,46 & 8,72 & 76,09 \\
\hline
\end{tabular}

Análise realizada no laboratório de análise de solo do Sindicato Rural de Maringá.

Tabela 2. Composição granulométrica e densidade média do solo da área de cultivo da cultura do pepino.

\begin{tabular}{ccccc}
\hline $\begin{array}{c}\text { Areia grossa } \\
\left(\mathrm{g} \mathrm{kg}^{-1}\right)\end{array}$ & $\begin{array}{c}\text { Frações granulométricas } \\
\text { Areia fina } \\
\left(\mathrm{g} \mathrm{kg}^{-1}\right)\end{array}$ & $\begin{array}{c}\text { Silte } \\
\left(\mathrm{g} \mathrm{kg}^{-1}\right)\end{array}$ & $\begin{array}{c}\text { Argila } \\
\left(\mathrm{g} \mathrm{kg}^{-1}\right)\end{array}$ & $\begin{array}{c}\text { Densidade do solo } \\
\left(\mathrm{Mg} \mathrm{m}^{-3}\right)\end{array}$ \\
\hline 50,0 & 72,6 & 120,6 & 756,8 & 1,02 \\
\hline
\end{tabular}

Análise realizada no laboratório de análise de solo do Sindicato Rural de Maringá.

A análise de solo apresentou concentrações de nutrientes insuficientes para o cultivo de pepino, seguindo a recomendação de Ribeiro et al. (1999) foi realizada a aplicação de $120 \mathrm{~kg} \mathrm{ha}^{-1}$ de $\mathrm{N}$, e $180 \mathrm{~kg} \mathrm{ha}^{-1}$ de $\mathrm{K}_{2} \mathrm{O}$ e $180 \mathrm{~kg} \mathrm{ha}^{-1}$ de $\mathrm{P}_{2} \mathrm{O}_{5}$, aplicando o fósforo foi realizada no transplante e outros nutrientes em cobertura, conforme recomendado por Trani (2014). A cultura do pepino foi conduzida em canteiros espaçados $0,80 \mathrm{~m}$ entre si, com $0,20 \mathrm{~m}$ de largura, $0,20 \mathrm{~m}$ de altura e 3,0 m de comprimento. Mudas de pepino japonês Hokushin foram cultivadas em bandejas de polietileno de 162 células.

O manejo das plantas foi realizado através da poda de seus ramos visando o tutoramento das mesmas. Essa poda, melhora a relação fonte e dreno da planta a qual estabiliza sua altura e induz a produção de ramificações laterais, dando continuidade ao crescimento lateral, aumentando as fontes (folhas) e consequentemente os drenos (frutos) (SANTI et al., 2013).

$\mathrm{O}$ experimento foi conduzido em delineamento inteiramente ao acaso (DIC) com quatro níveis de reposição de lâminas relativa a evapotranspiração da cultura $(75 \%, 100 \%$, $125 \%$ e $150 \%$ da ETc) e quatro repetições cada totalizando 16 parcelas experimentais.
As irrigações foram realizadas com base no cálculo da ETc. A evapotranspiração de referência $\left(\mathrm{ET}_{0}\right)$ foi determinada pela equação de Penman-Monteith (ALLEN et al., 1998) com base nas variáveis climatológicas medidas no interior do ambiente protegido por meio da estação climatológica automática Campbel Scientific (com sensores de temperaturas, umidade relativa, velocidade do vento e radiação), ajustada para coletar dados a cada 2 segundos e disponibilizar a média de cada variável em intervalos de 30 minutos, armazenados em data loger CR1000.

Ao final de cada dia, os dados eram coletados e a $\mathrm{ET}_{0}$ diárias eram calculadas com a equação de Penman-Monteith. Adotou-se o coeficiente da cultura (Kc) estimado por Blanco e Folegatti (2003) para a determinação da lâmina de irrigação a ser aplicada (ETc).

Foi utilizado o sistema de irrigação por gotejamento, com dois gotejadores autocompensantes com vazão de $8 \mathrm{~L} \mathrm{~h}^{-1}$ por planta, operando a 15 mca. A pressão foi controlada com auxílio de um manômetro com glicerina instalado no cabeçal de controle do sistema.

A curva parcial de retenção de água no solo foi determinada através da metodologia utilizada por Almeida et al. (2010), que consiste em instalar uma série de tensiômetros e estimar a umidade do solo através de séries 
de sondas de TDR na profundidade onde se encontra as raízes das plantas, obtendo a umidade do solo pela tensão.

Neste caso, foram utilizados 9 tensiômetros e 9 sondas de TDR instalados na profundidade de $15 \mathrm{~cm}$. O solo foi umedecido até sua saturação e após 6 horas iniciou-se as leituras durante o período de três dias. Os valores foram ajustados ao modelo de VanGenuchten e os respectivos coeficientes são apresentados na Equação 1.

$$
\theta=0,2191+\frac{0,4334-0,2191}{\left[1+(0,1738 \times \psi \mathrm{m})^{1,9320}\right]^{0,6911}}
$$

Em que as variáveis são:

$\theta=$ umidade volumétrica $\left(\mathrm{m}^{3} \mathrm{~m}^{-3}\right)$;

$\Psi=$ tensão de água no solo $(\mathrm{kPa})$.

Com a Equação 1, encontrou lâmina de irrigação de $24 \mathrm{~mm}$ para a camada de 0 a 30 $\mathrm{cm}$, que representa a elevação do potencial de água de -30 a $-10 \mathrm{kPa}$. Justificou-se a não consideração das perdas por percolação profunda na equação do balanço hídrico, uma vez que a maior lâmina de irrigação requerida foi igual a $20,1 \mathrm{~mm}$. Com a curva, foram realizadas medições diárias de tensão a $15 \mathrm{~cm}$, para monitorar a umidade média no sistema radicular, 30 e $50 \mathrm{~cm}$, para monitorar se estaria ocorrendo percolação, essas medidas foram realizadas nas parcelas nas quais foi aplicado $100 \%$ da lâmina relativa à ETc.
Utilizou-se essa metodologia para o manejo das irrigações realizadas nos tratamentos de $100 \%$ da ETc, com intuito de verificar se o $\mathrm{Kc}$ proposto por Blanco e Folegatti (2003) estava suprindo as necessidades hídricas para o ambiente protegido. Os tensiômetros instalados a $50 \mathrm{~cm}$ não indicaram variação de tensão com as realizações das irrigações, evidenciando que o Kc adaptou-se ao ambiente e garantiu também que não houvesse perda por percolação profunda.

A colheita iniciou-se aos 32 dias após o transplantio (DAT) e se prolongou até o final do experimento aos 97 DAT, sendo realizada em dias alternados. Seguindo as recomendações de Carvalho et al. (2013), o ponto adotado para a colheita foi o comprimento dos frutos maior que $20 \mathrm{~cm}$ e diâmetro acima de $3 \mathrm{~cm}$.

A quantificação das raízes foi realizada no final do ciclo da cultura por meio de um amostrador de chapas de aço com as dimensões de $20 \mathrm{~cm}$ de largura, $25 \mathrm{~cm}$ de comprimento e $30 \mathrm{~cm}$ de profundidade (Figura 1a). As dimensões do amostrador foram adotadas conforme as dimensões do canteiro.

$\mathrm{Na}$ amostragem de raízes o amostrador foi introduzido no solo de forma nivelada (Figura 1b). As amostras retiradas foram lavadas com água e eram retidas em peneira de tela de arame galvanizado malha 4, posteriormente acondicionadas em sacos de papel e levadas a estufa de ventilação forçada, à $\pm 65^{\circ} \mathrm{C}$, até obter massa constante.

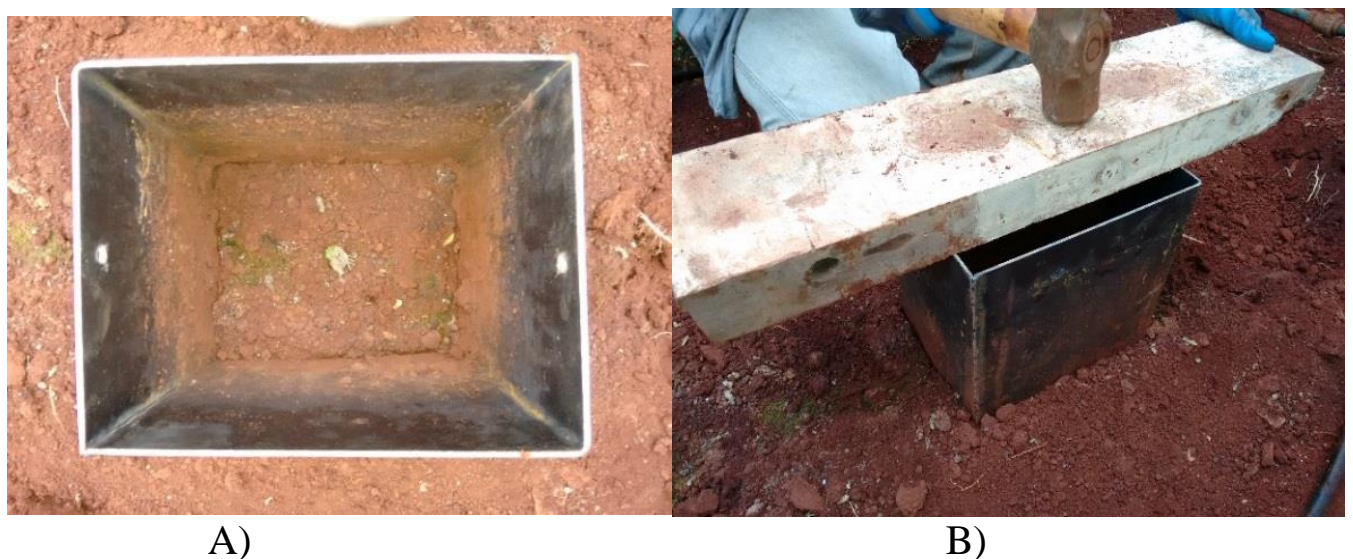

A)

B)

Figura 1. A) Vista superior do amostrador de raízes. B) Exemplo de amostragem a campo. 
A eficiência de utilização de água foi determinada por meio da razão entre produtividade $\left(\mathrm{kg}\right.$ planta $\left.^{-1}\right)$ e quantidade de água aplicada $(\mathrm{mm})$ em cada tratamento (COELHO et al., 2013)

Os dados foram submetidos a análise de variância com o auxílio do programa SISVAR (FERREIRA, 2014). Uma vez detectadas diferenças significativas entre os tratamentos, foram ajustadas regressões.

\section{RESULTADOS E DISCUSSÃO}

Na Tabela 3 são apresentados os valores da análise de variância. Podese notar que houve diferenças significativas para produtividade e massa seca de raiz em função das lâminas de água. Também são apresentadas as médias obtidas para cada variável analisada.

Tabela 3. Analise de variância.

\begin{tabular}{cccc}
\hline \multirow{2}{*}{ FV } & \multicolumn{3}{c}{ F valor } \\
\cline { 2 - 4 } & Produtividade & Massa de raiz & Eficiência de utilização da água \\
\hline ETc & $9,311^{* *}$ & $11,599 * *$ & $2,63 *$ \\
\hline CV $(\%)$ & 18,9 & 5,69 & 20,95 \\
Média & 7130,27 & 11,846 & 18,93 \\
\hline
\end{tabular}

** Significativo a $\mathrm{p}<1 \% \mathrm{e} *$ significativo a $\mathrm{p}<5 \%$.

Encontrada as diferenças (Tabela 3), foi realizado o estudo da regressão sendo que o modelo polinomial teve melhor ajuste para as variáveis $(t<0,05)$, com as equações ajustadas e seus coeficientes de determinação apresentadas nas Figuras 3, 4 e 5.

As lâminas médias de água acumuladas foram de 274,26; 341,41; 408,56 e 475,71 mm correspondendo, respectivamente, a reposição de $75,100,125$ e $150 \%$ da ETc da cultura do pepino japonês (Figura 2a). A maior temperatura registrada no período foi de $42,4^{\circ} \mathrm{C}$, a mínima foi de 14,3 ${ }^{\circ} \mathrm{C}$ e a média de $28,2{ }^{\circ} \mathrm{C}$. Para a umidade relativa do ar, a máxima, mínima e média encontradas foram de 100, 70 e 96\%, respectivamente (Figura $2 \mathrm{~b}$ ). De acordo com as temperaturas medidas não houve registro de temperatura fora da faixa ideal de cultivo do pepino de acordo com Alsadon et al. (2016).

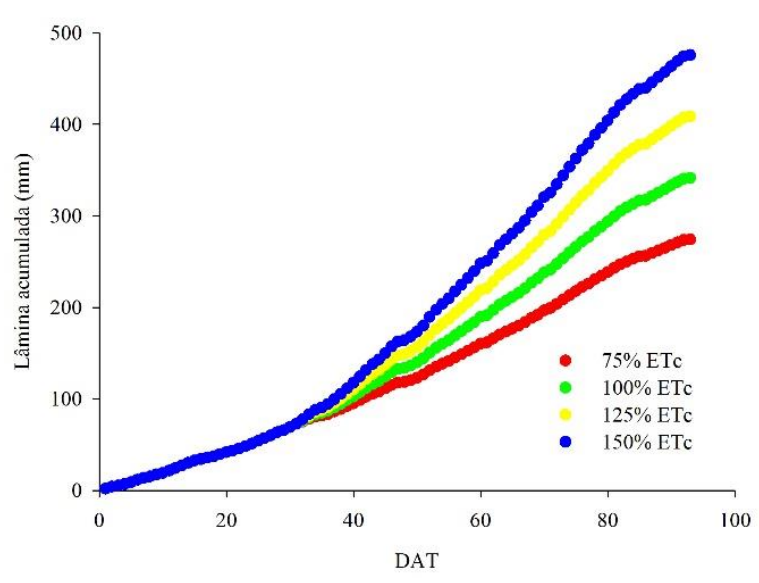

a)

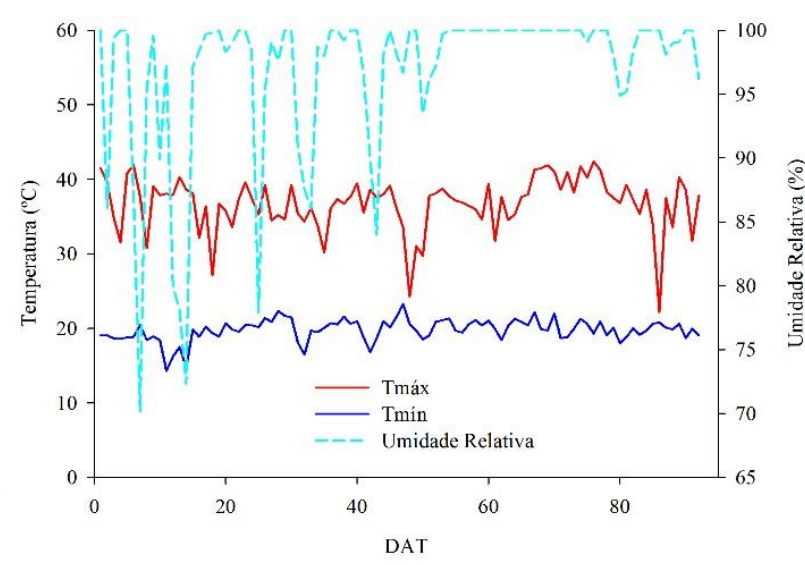

b)

Figura 2. a) Lâminas médias acumuladas ao longo do ciclo. b) Temperatura máxima e mínima e umidade relativa coletadas ao longo do ciclo.

A aplicação dos diferentes níveis de reposição de lâminas relativa a ETc promoveram diferenças significativas $(\mathrm{p}<0,05)$ para a variável massa de frutos, obtendo a 
maior produção com a lâmina $128 \%$ da ETc (Figura 3). O ajuste da resposta da variável massa de frutos por nível de reposição de lâmina foi ajustado por modelo quadrático.
O valor máximo de produção de frutos com a reposição da lâmina de água relativa a ETc foi $2190 \mathrm{~g}$ planta $^{-1}$, sendo que o valor é associado a reposição de $128 \%$ da ETc (Figura $3)$.

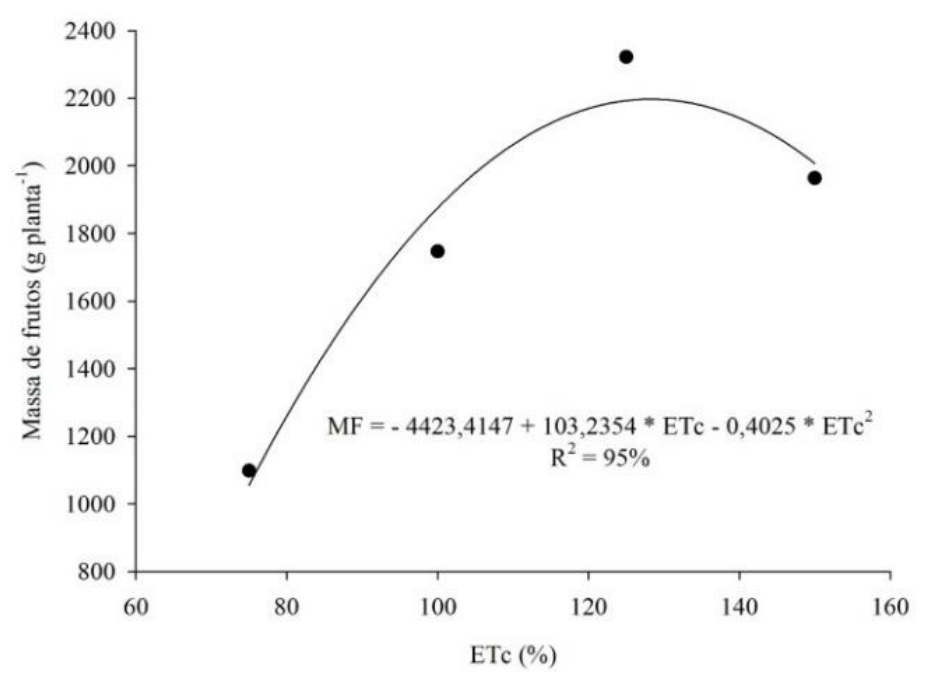

Figura 3. Massa de frutos para a cultura do pepino cultivado em ambiente protegido.

A menor lâmina aplicada (75 \% ETc) obteve o menor valor para a variável massa de frutos corroborando com o trabalho desenvolvido com 50, 75, 100, 125 e $150 \%$ da ETc (OLIVEIRA et al., 2011).

Já o excesso de umidade em torno do sistema radicular da planta dificulta $o$ arejamento e provoca, assim, anomalias de origem fisiológica e a lixiviação de nutrientes; desta forma, onera a cultura sem nenhum beneficio, representando também desperdício de água e energia, dois sérios problemas no mundo atual (FILGUEIRA, 2008). Santana et al. (2009) também verificou a redução do rendimento com reposições excessivas de água no solo.

Santi et al. (2013), obteve produção de $3,4 \mathrm{~kg}$ planta $^{-1}$, valor superior ao encontrado no presente trabalho. Segundo Carvalho et al. (2013) a variação da produtividade da cultura do pepino varia entre 1 a $5 \mathrm{~kg}$ planta $^{-1}$, de acordo com o período de condução da cultura.

Buttaro et al. (2015) não verificou diferença significativa na produção de pepino comparando-se a aplicação de água quando o solo tinha potencial de -30 e $-10 \mathrm{kPa}$. No entanto, o manejo da irrigação com o menor potencial resultou em economia de água de $46 \%$. Esses resultados permitem constatar que a irrigação em excesso não promove benefícios a cultura e pode levar o desperdício de água e energia, resultados encontrados no presente trabalho.

Para a variável massa seca de raízes, o valor máximo foi $12,8 \mathrm{~g}_{\text {planta }}{ }^{-1}$ associado a reposição de $114 \%$ da ETc, conforme pode ser observado na Figura 4. O ajuste da resposta da variável massa seca de raízes por nível de reposição de lâmina foi ajustado por modelo quadrático. 


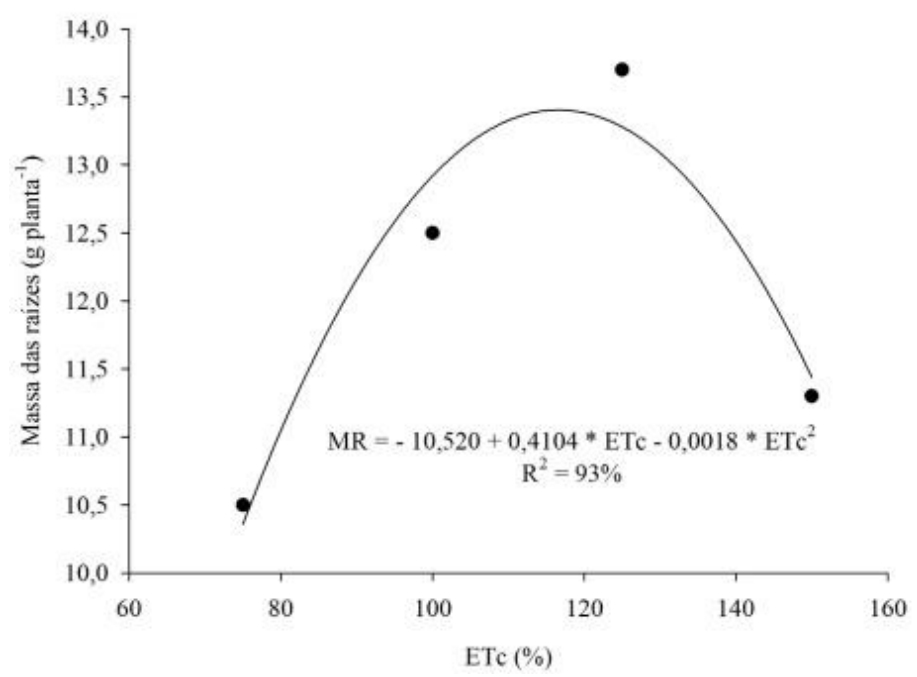

Figura 4. Massa seca de raízes para a cultura do pepino cultivado em ambiente protegido.

O solo seco é composto pela fase sólida e gasosa. Ao elevar a umidade do solo, a água ocupa os poros anteriormente preenchidos por ar, reduzindo a disponibilidade de oxigênio. A condição de falta absoluta de oxigênio, ou anoxia, só pode ser observada em solos alagados (GREENWAY et al., 2006).

O oxigênio é o aceptor final de elétrons da respiração, processo que tem por finalidade a oxidação completa de compostos de carbono a gás carbônico e água, sendo este processo a principal via utilizada pela raíz para a obtenção de energia (TAIZ; ZEIGER, 2013). Plantas em solos com insuficiente aeração tendem a apresentar redução do crescimento das raízes e consequentemente na produção (FRIEDMAN; NAFTALIEV, 2012).

$\mathrm{O}$ déficit de oxigênio é mais frequente em solos de textura argilosa do que arenosa devido a maior capacidade de retenção de água e menores coeficientes de difusão de $\mathrm{O}_{2}$ dos primeiros em relação aos últimos (FRIEDMAN; NAFTALIEV, 2012). O solo argiloso da área experimental pode ter contribuído para a ocorrência do déficit de oxigênio, o que pode estar relacionado com a redução da produção e da massa seca de raízes com reposição de lâmina de água acima de $114 \%$ da ETc.

A aplicação localizada de água aumenta a umidade na zona radicular à condição próxima da saturação, o que reduz disponibilidade de oxigênio por horas após a aplicação de água. O problema pode ser solucionado por meio da aeração do solo logo antes da irrigação (NIU et al., 2012). Isso permite concluir que a irrigação deve propiciar um balanço favorável entre umidade e aeração do solo.

A partir da equação ajustada na Figura 4, obtive o valor de máximo crescimento radicular em função da lâmina de reposição, a qual foi de $114 \%$ da ETc, mostrando que tanto o déficit hídrico e o excesso hídrico constante prejudica a aeração do solo causando a diminuição do desenvolvimento das raízes (TAIZ; ZEIGER, 2013).

Soratto et al. (2003) estudando manejo de água na cultura do feijoeiro afirma que possivelmente pode ocorrer o apodrecimento do sistema radicular quando se faz irrigações em excesso causando assim possíveis perdas na produtividade, o que é mostrado no caso para o pepino com o crescimento radicular menor e menor produção na lâmina de reposição de $150 \%$ da ETc.

O ajuste da resposta da variável eficiência de utilização da água por nível de reposição de lâmina foi ajustado por modelo quadrático. 


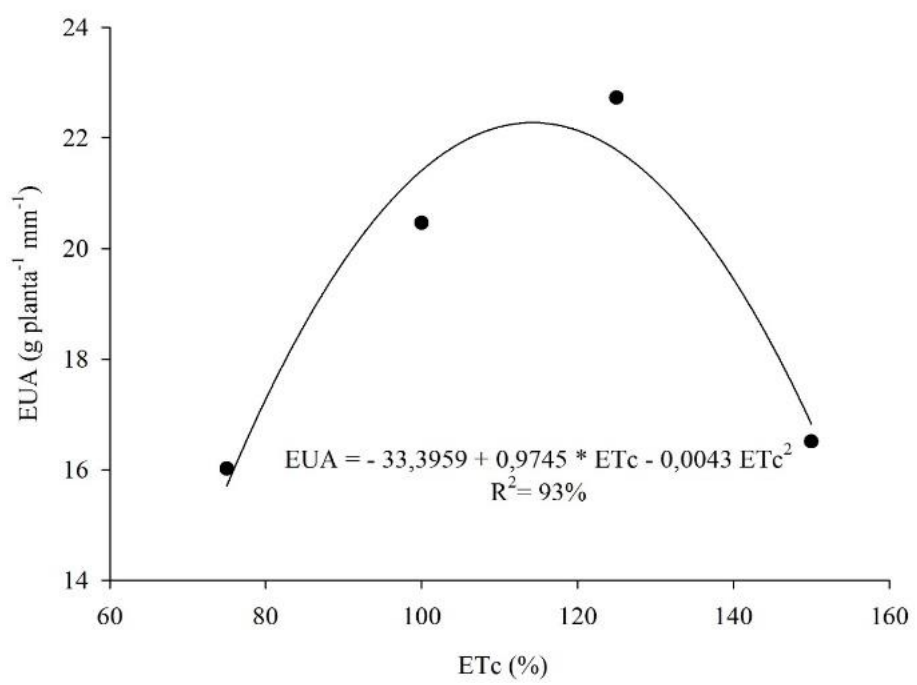

Figura 5. Eficiência do uso da água da cultura do pepino japonês.

Para a eficiência de utilização da água ocorreu a melhor relação próximo a lâmina correspondente a de $121 \%$ da ETc $(317,47$ $\mathrm{mm})$, com um ganho de $21,5 \mathrm{~g}_{\text {planta }}{ }^{-1} \mathrm{~mm}^{-1}$ (Figura 5).

$\mathrm{O}$ excesso de umidade em torno do sistema radicular da planta dificulta a aeração podendo representar o desperdício de água e energia (FILGUEIRA, 2008).

Zhang et al. (2011) compararam a produção de pepino em tratamentos de $60 \%$, $80 \%$ e $100 \%$ da reposição de água ao solo medida por meio de um mini tanque. No último tratamento, a variação do armazenamento de água foi positiva, o que leva a concluir que a reposição de água foi maior que o consumo de água pela cultura, enquanto que nos demais tratamentos, a variação do armazenamento foi negativa. Os autores concluíram que o tratamento de $80 \%$ da reposição teve eficiência de utilização da água de irrigação superior aos demais.

Rahil e Qanadillo (2015) observaram que a reposição de $70 \%$ da ETc na cultura do pepino em ambiente protegido teve maior produtividade e eficiência de utilização de água do que a reposição de $100 \%$ da ETc.

Estes resultados indicaram que houve consistência da relação entre a produção e a eficiência de utilização de água, pois ambos tiveram o ponto de máxima próximos. Oliveira et al. (2011), estudando a lâmina ótima econômica para a cultura do pepino encontraram valores próximos de máxima utilização de água com $319,5 \mathrm{~mm}$, resultados próximos ao encontrado no presente trabalho.

Fazendo-se uma análise comparativa entre a lâmina de maior rendimento e a lâmina que gera a máxima produtividade física, observam-se valores semelhantes de produtividade. Logo, ao se aplicar a lâmina de água que proporcione a máxima produtividade da cultura, ela poderá ser suficiente para alcançar a melhor eficiência de utilização da água, indicando que a irrigação deve ser feita de forma a manter as condições ótimas de umidade no solo e garantir o pleno desenvolvimento vegetativo.

\section{CONCLUSÕES}

A maior produtividade $\left(2,19 \mathrm{~kg} \mathrm{planta}^{-1}\right)$ com a reposição de lâmina a de $386,97 \mathrm{~mm}$ (128\% da ETc), e o maior crescimento das raízes (12,8 $\left.\mathrm{g} \mathrm{planta}^{-1}\right)$ com a lâmina de reposição de $343 \mathrm{~mm}$ (114\% da ETc).

A maior eficiência de utilização da água foi obtida com a lâmina de $121 \%$ da ETc, notando que um aumento sobre a lâmina de referência (100\% ETc) é uma alternativa na gestão de recursos hídricos para aumentar a produtividade da cultura.

\section{REFERÊNCIAS}


ALI, M. H.; TALUKDER, M. S. U. Increasing water productivity in crop production-A synthesis. Agricultural Water Management, Amsterdam - Holanda. v. 95, p 1201-1213, 2008.

ALLEN RG, PEREIRA LS, RAES D, SMITH M. Crop evapotranspiration-Guidelines for computing crop water requirements-FAO Irrigation and drainage paper 56. FAO, Rome, v. 300, n. 9, p. D05109, 1998

ALMEIDA, A. S.; ARAÚJO, F. S.; SOUZA, G. S. Determinação da curva parcial de retenção de água de um latossolo vermelho por tensiomêtria. Scientia Plena, Aracaju-SE, v. 6, n. 9, p. 1-5, 2010.

ALSADON, A., AL-HELAL, I., IBRAHIM, A., ABDEL-GHANY, A., AL-ZAHARANI, S., ASHOUR, T. The effects of plastic greenhouse covering on cucumber (Cucumis sativus L.) growth. Ecological Engineering, Lublin - Polônia, v. 87, p. 305-312, 2016.

BERNARDO, S. Manual de irrigação. 6. ed. Viçosa - MG: UFV, 1995. 656 p.

BLANCO, F. F. Fertirrigação na cultura do pepino. Teresina - PI, p. 305-330, 2002

BLANCO, F. F.; FOLEGATTI, M. V. Evapotranspiration and crop coefficient of cucumber in greenhouse. Revista Brasileira de Engenharia Agrícola e Ambiental, Campina Grande - PB, v. 7, n. 2, p. 285-291, 2003.

BUTTARO, D., SANTA MARIA, P., SIGNORE, A., CANTORE, V., BOARI, F., MONTESANO, F. F., PARENTE, A, DONATO. Irrigation management of greenhouse tomato and cucumber using tensiometer: effects on yield, quality and water use. Agriculture and Agricultural Science Procedia, Saskaton - Canadá, v. 4, p. 440-444, 2015.
ÇAKIR, R.; KANBUROGLU-ÇEBI, U.; ALTINTAS, S.; OZDEMIR, A. Irrigation scheduling and water use efficiency of cucumber grown as a spring-summer cycle crop in solar greenhouse. Agricultural Water Management, Amsterdam - Holanda, v. 180, p. 78-87, 2017.

CARDOSO, A. I. I.; SILVA, N. DA. Avaliação de híbridos de pepino tipo japonês sob ambiente protegido em duas épocas de cultivo. Horticultura Brasileira, Brasília DF, v. 21, p. 171-176, 2003.

CARVALHO, A. D. F.; AMARO, G. B.; LOPES, J. F.; VILELA, N. J.; FILHO, M. M.; ANDRADE, R. A cultura do pepino. Embrapa hortaliças, Brasília - DF, p. 18 p., 2013 (Circular Técnica 113).

COELHO, M. E. H.; FREITAS, F. C. L.; CUNHA, J. L. X. L.; MEDEIROS, J. F.; SILVA, M. G. O. Production and efficiency of water usage in capsicum crops under notillage and conventional planting systems. Revisa Ciência Agronômica, Fortaleza - Ceará, v. 44, n. 4, p. 741-749, 2013.

EMBRAPA: Centro Nacional de Pesquisa de Solos, 2 ed. Rio de Janeiro: Embrapa Solos, 2006.

FERREIRA, D. F. Sisvar: a Guide for its Bootstrap procedures in multiple comparisons. Ciência e Agrotecnologia, Lavras - MG, v. 38, n. 2, p. 109-112, 2014.

FILGUEIRA, F.A.R. Novo manual de oleiricultura: Agrotecnologia moderna na produção e comercialização de hortaliças. 3 ed. Viçosa - MG, Ed UFV, 2008, 421p.

FRIEDMAN, S. P.; NAFTALIEV, B. A survey of the aeration status of drip-irrigated orchards. Agricultural Water Management, Amsterdam - Holanda, v. 115, p. 132-147, 2012.

GREENWAY, HANK; ARMSTRONG, WILLIAM; COLMER, TIMOTHY D. 
Conditions leading to high $\mathrm{CO} 2(>5 \mathrm{kPa})$ in waterlogged-flooded soils and possible effects on root growth and metabolism. Annals of Botany, Londres - Inglaterra, v. 98, n. 1, p. 932, 2006.

LIEBIG, H.P. Physiological and economical aspects of cucumber crop density. Acta Horticulturae, Korbeek-Lo Belgica, n.118, p.149-164, 1981.

MENDES, E. S. Uso consultivo de água pela alface (Lactuca sactiva L.) cultivares Verônica (crespa) e Elisa (lisa) pelo método da irrigação e percolação. 2009. 30 p. Instituto Federal do Sul de Minas Inconfidentes, MG.

NIU, W., GUO, Q., ZHOU, X., HELMERS, M. J, WENQUAN. Effect of aeration and soil water redistribution on the air permeability under subsurface drip irrigation. Soil Science Society of America Journal, Washington EUA, v. 76, n. 3, p. 815-820, 2012.

OLIVEIRA, E. C.; CARVALHO, J. D. A; SILVA, W. G.; REZENDE, F. C.; GOMES, L. A A; JESUS, M. C. N. DE. Análise produtiva e econômica do pepino japonês submetido a diferentes lâminas de irrigação. Revista Brasileira de Engenharia Agrícola e Ambiental, Campina Grande - PB, v. 15, n. 35, p. 702-708, 2011.

RAHIL, M. H., QANADILLO, A. Effects of different irrigation regimes on yield and water use efficiency of cucumber crop. Agricultural water management, Amsterdam - Holanda, v. 148, p. 10-15, 2015.

RIBEIRO, A. C.; GUIMARÃES, P. T. G.; ALVAREZ, V. H. Recomendações para uso de corretivos e fertilizantes em Minas Gerais - $\mathbf{5}^{\mathbf{0}}$ aproximação. Viçosa - MG, [s.n.], $1999 . \quad$ Disponível em: http://www.labominas.com.br/userfilesfiles/5aproximacao.pdf

SANTANA, M. J. DE; CARVALHO, J. A.; ANDRADE, M. J. B. DE; GERVÁSIO, G. G.;
BRAGA, J. C.; LEPRI, E. B. Viabilidade técnica e econômica da aplicação de água na cultura do feijoeiro comum (Phaseolus vulgaris L.). Ciência e Agrotecnologia, Lavras - MG, v.33, p.532-538, 2009.

SALOKHE, V. M., BABEL, M. S., TANTAU, $\mathrm{H}$. Water requirement of drip irrigated tomatoes grown in greenhouse in tropical environment. Agricultural Water Management, Amsterdam - Holanda, v. 71, n. 3, p. 225-242, 2005.

SANTI, A.; SCARAMUZZA, W. L. M. P.; SOARES, D. M. J.; SCARAMUZZA, J. F.; DALLACORT, R.; KRAUSE, W.; TIEPPO, R. C. Desempenho e orientação do crescimento do pepino japonês em ambiente protegido. Horticultura Brasileira, Bahia BA, v 31: p. 649-653, 2013.

SELEGUINI, A.; SENO, S.; LEMOS, O. L.; FARIA JÚNIOR, M. J. A. Produção hidropônica de pepino japonês em função de recipientes e densidades de plantio. Horticultura Brasileira, Bahia - BA, v.25, n.1, 2007.

SILVA, G. F. DA; FONTES, P. C. R.; LIMA, L. P. F. DE; ARAÚJO, T. O. DE; SILVA, L. DE F. Aspectos morfoanatômicos de plantas de pepino (Cucumis sativus L.) sob omissão de nutrientes. Revista Verde de Agroecologia e Desenvolvimento Sustentável, Pombal - PB, v. 6, p. 13-20, 2011.

TAIZ, L.; ZEIGER, E. Fisiologia vegetal. 5. Ed. Porto Alegre -RS: Artmed, 2013. 918p.

TRANI, P. E. Calagem e adubação para hortaliças sob cultivo protegido. Instituto Agronômico de Campinas. Campinas, 2014.

ZHANG, H. X., CHI, D. C., QUN, W., JUN, F. A. N. G., \& FANG, X. Y. Yield and quality response of cucumber to irrigation and nitrogen fertilization under subsurface drip irrigation in solar greenhouse. Agricultural Sciences in China, Haidian District - China, v. 10, n. 6, p. 921-930, 2011. 